\title{
Comparisons of Four Protein-Binding Models Characterizing the Pharmacokinetics of Unbound Phenytoin in Adult Patients Using Non-Linear Mixed-Effects Modeling
}

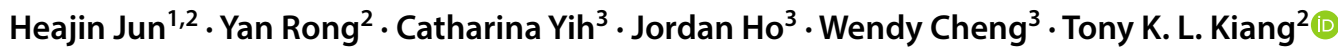

Accepted: 19 September 2020 / Published online: 7 October 2020

(c) The Author(s) 2020

\begin{abstract}
Background and objective Phenytoin is extensively protein bound with a narrow therapeutic range. The unbound phenytoin is pharmacologically active, but total concentrations are routinely measured in clinical practice. The relationship between free and total phenytoin has been described by various binding models with inconsistent findings. Systematic comparison of these binding models in a single experimental setting is warranted to determine the optimal binding behaviors.

Methods Non-linear mixed-effects modeling was conducted on retrospectively collected data ( $n=37$ adults receiving oral or intravenous phenytoin) using a stochastic approximation expectation-maximization algorithm in MonolixSuite-2019R2. The optimal base structural model was initially developed and utilized to compare four binding models: Winter-Tozer, linear binding, non-linear single-binding site, and non-linear multiple-binding site. Each binding model was subjected to error and covariate modeling. The final model was evaluated using relative standard errors (RSEs), goodness-of-fit plots, visual predictive check, and bootstrapping.

Results A one-compartment, first-order absorption, Michaelis-Menten elimination, and linear protein-binding model best described the population pharmacokinetics of free phenytoin at typical clinical concentrations. The non-linear single-bindingsite model also adequately described phenytoin binding but generated larger RSEs. The non-linear multiple-binding-site model performed the worst, with no identified covariates. The optimal linear binding model suggested a relatively high binding capacity using a single albumin site. Covariate modeling indicated a positive relationship between albumin concentration and the binding proportionality constant.

Conclusions The linear binding model best described the population pharmacokinetics of unbound phenytoin in adult subjects and may be used to improve the prediction of free phenytoin concentrations.
\end{abstract}

Electronic supplementary material The online version of this article (https://doi.org/10.1007/s40268-020-00323-2) contains supplementary material, which is available to authorized users.

Tony K. L. Kiang

tkiang@ualberta.ca

1 College of Pharmacy, Seoul National University, Seoul, Republic of Korea

2 Faculty of Pharmacy and Pharmaceutical Sciences, University of Alberta, Katz Group Centre for Pharmacy and Health Research, Room 3-142D, 11361-87 Avenue, Edmonton, AB T6G 2E1, Canada

3 Department of Pharmacy, Vancouver General Hospital, Vancouver, BC, Canada

\section{Key Points}

A systematic comparison of four binding-dissociation models (i.e. Winter-Tozer, linear binding, non-linear single-binding site, and non-linear multiple-binding site) within a fully developed population pharmacokinetic model indicated that phenytoin binding to serum albumin is non-saturable and affected by albumin concentration in adult patients at typical clinical free concentrations.

The final model suggested that phenytoin might be bound to a single site on albumin with a relatively high binding capacity. 


\section{Introduction}

Phenytoin has been one of the most widely prescribed anticonvulsants since its initial approval in the 1950s, although its usage has been slowly declining with the availability of newer-generation antiepileptic drugs with lower risks of drug-drug interactions [1-3]. Phenytoin is highly bound to plasma albumin $(\sim 90 \%)$ in healthy adults $[4,5]$, where unbound phenytoin is primarily eliminated by hepatic intrinsic clearance mediated by cytochrome P450 (CYP)2C9 and CYP2C19 [5-8]. Only minimal amounts of phenytoin $(\sim 1.2 \%)$ are excreted unchanged into the urine [9]. The CYP2C9/19-mediated oxidation of phenytoin is usually saturated at the typical phenytoin plasma concentrations observed clinically, leading to non-linear (i.e., Michaelis-Menten) elimination [6, 10]. Moreover, phenytoin is a broad spectrum inducer of metabolism enzymes [11, 12], which can increase the intrinsic clearance of coadministered drugs.

Therapeutic drug monitoring of phenytoin is recommended because of its narrow therapeutic range (i.e., 10-20 mg/L based on total concentrations), non-linear kinetics, and potential for drug-drug interactions [4, 13]. Loss of antiepileptic effect is typically evident at total phenytoin serum concentrations $<10 \mathrm{mg} / \mathrm{L}$ [14], whereas phenytoininduced neurotoxicity (e.g., nystagmus, fatigue) can usually be observed in patients with total serum concentrations $>20 \mathrm{mg} / \mathrm{L}[15,16]$. Hence, a delicate balance within this narrow therapeutic window is required. However, the attainment of phenytoin concentrations within the narrow target can be complicated by non-linear kinetics and other factors known to influence phenytoin's protein binding or intrinsic clearance (e.g., [4, 10, 13, 17]).

Pharmacologically active unbound phenytoin is the ideal marker for therapeutic drug monitoring. However, free phenytoin concentrations are not routinely measured because of the complexity of the analysis and the higher costs $[13,18]$. Therefore, phenytoin therapeutic drug monitoring is commonly conducted with the total concentration, and free concentrations are only estimated in patients with renal dysfunction and/or reduced albumin [13, 18]. Several approaches have been proposed to describe the relationship between free and total phenytoin by characterizing the binding of free phenytoin with serum albumin. The most widely used approach is the Winter-Tozer equation, which has been modified by many others to better tailor to individual patient populations [19-23]. Moreover, non-linear mixed-effects modeling has been used to predict unbound phenytoin concentrations and characterize the nature of protein binding. For example, Hennig et al. [24] used a proportional linear binding model in critically ill pediatric subjects, ter Heine et al. [25] validated a non-linear binding model in various populations, and various investigative groups examined clinical covariates influencing the protein binding or free fraction of phenytoin [24-27]. However, to our knowledge, individual phenytoin protein-binding models have never been directly compared in a single experimental setting, so the optimal binding model remains equivocal. The objective of this study was to systematically compare four individual protein-binding models (i.e., Winter-Tozer, linear binding, non-linear single-binding site, and non-linear multiple-binding site) within a fully developed population pharmacokinetic model to identify the optimal albumin-binding characteristics of phenytoin and the influence of clinical covariates.

\section{Methods}

\subsection{Patients and Study Design}

The study protocol was approved by the University of British Columbia (H18-02215) and the University of Alberta (Pro00100357) research ethics boards. Non-linear mixedeffects modeling was conducted on retrospectively collected data from Vancouver General Hospital in Vancouver, British Columbia, Canada. Data from patients aged $>18$ years receiving oral or intravenous phenytoin were included. Paired measurements of free and total phenytoin concentrations were extracted from the hospital electronic database between 31 August 2014 and 31 August 2018. All included patients received at least 5 days of the same phenytoin regimen. Patients were excluded if they were admitted to the emergency department at the time of receiving phenytoin or lacked clinical laboratory values. A total of 37 patients with 37 paired free and total phenytoin concentrations were included in this study. The following data were collected: sex, critical care status (i.e., admission to the general or neurosurgical intensive care units), age, actual body weight, serum albumin, alanine transaminase (ALT), aspartate transaminase (AST), total bilirubin, international normalized ratio (INR), serum creatinine ( $\mathrm{SCr}$ ), hemodialysis status, and concomitant medications (i.e., low-dose aspirin, carbamazepine, heparin, phenobarbital, sulfonamides, valproic acid, or warfarin). The majority of laboratory values were gathered on the same day, and all values were obtained within 1 week of phenytoin concentration collection. Glomerular filtration rate (GFR) was estimated using the chronic kidney disease epidemiology collaboration equation [28]. Phenytoin plasma samples were collected 3-24 h after dose administration. Free and total phenytoin plasma concentrations were analyzed at the Vancouver General Hospital clinical laboratory as part of routine care using a validated immunoassay [29]. Throughout the entire manuscript, all phenytoin concentrations are designated as the free (unbound) concentration unless otherwise specified (i.e., total, bound). 


\subsection{Model Development}

\subsubsection{Software}

Modeling was conducted using a stochastic approximation expectation-maximization algorithm in MonolixSuite2019R2 (Lixoft SAS, Antony, France). For covariate and bootstrapping analyses, we used the Rsmlx package (Rsmlx, version 2.0.2, Xpop Inria Team) with R software v3.6.3 (R Core Team, Vienna, Austria).

\subsubsection{Base Model Selection}

First-order extravascular absorption with and without lag time or transit compartments were tested to describe phenytoin oral absorption. One- or two-compartment structural models were evaluated to obtain the best fit for free phenytoin concentration-time profiles. To describe the elimination of free phenytoin, we examined linear and Michaelis-Menten models. Based on the literature [19-25, 30-32], protein-binding relationships of phenytoin could be characterized by four types of binding-dissociation models, described as follows:

(1) Empiric Winter-Tozer equation [19] with an albumin coefficient [20-23],

$C_{\text {total }}=C_{\text {free }} \times(\mathrm{CF} \times$ albumin +0.1$) \times 10$

where $C_{\text {free }}(\mathrm{mg} / \mathrm{L})$ is the free phenytoin concentration, $C_{\text {total }}$ $(\mathrm{mg} / \mathrm{L})$ is the total concentration, $\mathrm{CF}$ is the albumin coefficient, and albumin is expressed in $\mathrm{g} / \mathrm{dL}$.

(2) Linear binding model with the assumption that $C_{\text {bound }}$ is directly proportional to $C_{\text {free }}$ with no saturable mechanism [24, 33],

$C_{\text {total }}=C_{\text {free }}+C_{\text {bound }}=C_{\text {free }}+K_{\mathrm{b}} \times C_{\text {free }}$

where $C_{\text {bound }}(\mathrm{mg} / \mathrm{L})$ is the bound concentration and $K_{\mathrm{b}}$ is the binding proportionality constant (i.e., $C_{\text {bound }} / C_{\text {free }}$ ).

(3) Non-linear binding model with the assumption that phenytoin binds to a single site on albumin [25, 31],

$C_{\text {total }}=C_{\text {free }}+\frac{B_{\text {max }} \times C_{\text {free }}}{K_{\mathrm{D}}+C_{\text {free }}}$

where $B_{\max }(\mathrm{mg} / \mathrm{L})$ represents the maximal binding capacity and $K_{\mathrm{D}}(\mathrm{mg} / \mathrm{L})$ defines the equilibrium dissociation constant (i.e., free concentration at which $50 \%$ of the binding site is occupied).

(4) Non-linear binding model with the assumption that phenytoin binds to more than one saturable binding site [30-32],

$$
C_{\text {total }}=C_{\text {free }}+\sum \frac{B_{\text {max }, i} \times C_{\text {free }}}{K_{\mathrm{D}, i}+C_{\text {free }}}
$$

where $B_{\max , i}$ and $K_{\mathrm{D}, i}$ are the binding-dissociation parameters of the $i$ th binding site of albumin.

Combined, proportional, or constant error models with normal, lognormal, or logit-normal distributions were tested. The most suitable structural, protein binding, and error models were selected based on biological plausibility, objective function values (OFVs), Akaike information criterion (AIC), Bayesian information criterion (BIC), relative standard errors (RSEs), and $\eta$-shrinkage values. A reduction in OFVs by more than 3.84 (i.e., $p<0.05$ ) was considered a significant improvement in modeling.

\subsubsection{Covariate Model Selection}

The four protein-binding models were further subjected to covariate analyses under identical pre-conditions (i.e., same structural model, error model, and initial parameter estimates) to identify the best final protein-binding model. The effects of an oral formulation (extended-release capsule or suspension) and clinical factors listed in Sect. 2.1 were assessed. For continuous factors, both original and natural log-transformed values were tested. The relationship between population pharmacokinetic parameters and covariates are provided in electronic supplementary material (ESM) 1 [34]. Clinical factors were identified as potential covariates by Pearson's correlation test $(p<0.05)$, the Wald test $(p<0.05)$, or stepwise forward inclusion using the R software (e.g., [35, 36]). All potential covariates were included in the base model and further subjected to stepwise backward elimination. The biological plausibility of all included covariates was assessed [4, 5, 13, 37, 38].

\subsection{Model Validation}

The final model was internally validated using goodnessof-fit plots, prediction-corrected visual predictive checks (pcVPC), and bootstrap analysis, as described previously $[35,36,39,40]$ (summarized in ESM 1).

\section{Results}

\subsection{Sample Population}

Data from 37 adult patients (mean age 61.1 \pm standard deviation 17.9 years) were available for analysis (Table 1). The majority $(73.0 \%)$ of the patients were male and classified as non-critical care $(56.8 \%)$. The average weight, AST, total bilirubin, INR, and SCr values (Table 1) were within the normal reference ranges $[41,42]$. However, a substantial portion 
Table 1 Patient demographics $(n=37)$

\begin{tabular}{|c|c|c|}
\hline Parameter & Mean \pm SD or count & Median (range) \\
\hline Sex (female/male) & $10 / 27$ & \\
\hline Critical care $(\mathrm{Y} / \mathrm{N})^{\mathrm{a}}$ & $16 / 21$ & \\
\hline Age (years) & $61.1 \pm 17.9$ & $62(20-93)$ \\
\hline Weight $(\mathrm{kg})$ & $68.5 \pm 15.6$ & $70(30-102)$ \\
\hline Albumin $(\mathrm{g} / \mathrm{dL})$ & $2.64 \pm 0.52$ & $2.7(1.7-3.6)$ \\
\hline ALT (IU/L) & $71.6 \pm 116.2$ & $36(13-693)$ \\
\hline AST (IU/L) & $42.8 \pm 37.1$ & $28(13-161)$ \\
\hline Total bilirubin $(\mu \mathrm{mol} / \mathrm{L})$ & $14.6 \pm 39.9$ & $6(2-249)$ \\
\hline INR & $1.1 \pm 0.1$ & $1.0(0.8-1.5)$ \\
\hline $\mathrm{SCr}(\mu \mathrm{mol} / \mathrm{L})$ & $96.8 \pm 91.6$ & $78(29-570)$ \\
\hline Hemodialysis $(\mathrm{Y} / \mathrm{N})^{\mathrm{b}}$ & $1 / 34$ & \\
\hline \multicolumn{3}{|l|}{ Current medications ${ }^{\mathrm{b}}$} \\
\hline Aspirin $(\mathrm{Y} / \mathrm{N})^{\mathrm{c}}$ & $10 / 26$ & \\
\hline Carbamazepine (Y/N) & $1 / 23$ & \\
\hline Heparin $(\mathrm{Y} / \mathrm{N})$ & $1 / 34$ & \\
\hline Phenobarbital $(\mathrm{Y} / \mathrm{N})$ & $1 / 34$ & \\
\hline Sulfonamides $(\mathrm{Y} / \mathrm{N})$ & $1 / 34$ & \\
\hline Valproic acid $(\mathrm{Y} / \mathrm{N})$ & $2 / 33$ & \\
\hline Warfarin $(\mathrm{Y} / \mathrm{N})$ & $1 / 34$ & \\
\hline \multicolumn{3}{|l|}{ Phenytoin dosage and measurements } \\
\hline Phenytoin dose (mg/day) & $378.5 \pm 148.3$ & $300(120-850)$ \\
\hline Administration route (IV/PO) & $16 / 21$ & \\
\hline Time between dose/test (h) & $12.9 \pm 7.3$ & $10.5(3.0-24.0)$ \\
\hline Total phenytoin concentration (mg/L) & $11.4 \pm 5.3$ & $9.8(5.3-23.5)$ \\
\hline Free phenytoin concentration (mg/L) & $1.4 \pm 0.7$ & $1.1(0.5-3.5)$ \\
\hline Unbound fraction $(\%)$ & $12.4 \pm 3.1$ & $11.8(7.1-19.4)$ \\
\hline
\end{tabular}

$A L T$ alanine transaminase, $A S T$ aspartate transaminase, INR international normalized ratio, $I V$ intravenous, $N$ no, $P O$ oral, $S C r$ serum creatinine, $S D$ standard deviation, $Y$ yes

apatients were considered under the category of "critical care" when admitted to either the general or the neurosurgical intensive care unit

${ }^{\mathrm{b}}$ Records were missing for some patients

${ }^{\mathrm{c}}$ Dose confirmed as $80 \mathrm{mg}$ orally daily in nine of ten subjects of patients (32.4\%) had increased ALT (i.e., > 53 IU/L), and a small portion of patients $(5.4 \%)$ had severe renal dysfunction (i.e., GFR $<30 \mathrm{~mL} / \mathrm{min} / 1.73 \mathrm{~m}^{2}$ ). Moreover, the majority of patients $(94.6 \%)$ had mild hypoalbuminemia (i.e., serum albumin $<3.5 \mathrm{~g} / \mathrm{dL}$ ), but the unbound fraction $(12.4 \pm 3.1 \%)$ was within the expected range [13]. On average, patients received $378.5 \pm 148.3 \mathrm{mg} /$ day of phenytoin in one to three divided doses, corresponding to a standard maintenance dose of 200-600 mg/day [43]. The reported total and free plasma phenytoin concentrations were also within the proposed monitoring targets (Table 1) $[4,18]$. A small number of patients received co-medications (Table 1).

\subsection{Base Model Selection}

Several combinations of structural, protein binding, and error models were tested (Table 2). A systematic approach was implemented to identify the most suitable base model: (1) initial search of the best model without considering protein binding (i.e., models 1-12 in Table 2), (2) screening of four different binding models that best complemented the identified structural model (i.e., models 13-16), and (3) testing for the optimal residual error models (i.e., models 13-28). For the structural model, the Michaelis-Menten elimination model was used because the free phenytoin concentrations in our dataset $(1.4 \pm 0.7 \mathrm{mg} / \mathrm{L})$ exceeded the literature-estimated $(0.40-0.73 \mathrm{mg} / \mathrm{L}[26,44])$ and modelestimated $\mathrm{Km}$ values (Table 3 ). Furthermore, a one-compartment structural model with first-order absorption without lag time best complemented the Michaelis-Menten elimination model (model 7) in our dataset based on likelihood estimations. Proportional errors were superior to both constant and combined models based on likelihood estimations (models 13-28) and goodness-of-fit plots (data not shown). 
Table 2 Base model selection history

\begin{tabular}{|c|c|c|c|c|c|c|c|c|}
\hline \multirow[t]{2}{*}{ Model } & \multicolumn{3}{|l|}{ Structural model } & \multirow[t]{2}{*}{ Protein-binding model } & \multirow[t]{2}{*}{ Error model } & \multirow[t]{2}{*}{ OFV } & \multirow[t]{2}{*}{ AIC } & \multirow[t]{2}{*}{$\mathrm{BIC}$} \\
\hline & Elimination & Distribution & Absorption & & & & & \\
\hline 1 & Linear & One-compartment & First-order with no delay & NA & Proportional & 72.08 & 82.08 & 90.14 \\
\hline 2 & Linear & One-compartment & First-order with lag time & NA & Proportional & 72.12 & 86.12 & 97.39 \\
\hline 3 & Linear & One-compartment & Transit-compartment & NA & Proportional & $70.84^{\mathrm{a}}$ & $88.84^{\mathrm{a}}$ & $103.33^{\circ}$ \\
\hline 4 & Linear & Two-compartment & First-order with no delay & NA & Proportional & 71.58 & 89.58 & 104.08 \\
\hline 5 & Linear & Two-compartment & First-order with lag time & NA & Proportional & $71.51^{\mathrm{a}}$ & $93.51^{\mathrm{a}}$ & $111.23^{\circ}$ \\
\hline 6 & Linear & Two-compartment & Transit-compartment & NA & Proportional & $70.95^{\mathrm{a}}$ & $96.95^{\mathrm{a}}$ & $117.89^{\circ}$ \\
\hline 7 & Michaelis-Menten & One-compartment & First-order with no delay & NA & Proportional & 89.21 & 103.21 & 114.48 \\
\hline 8 & Michaelis-Menten & One-compartment & First-order with lag time & NA & Proportional & $87.02^{\mathrm{a}}$ & $105.02^{\mathrm{a}}$ & $119.52^{\circ}$ \\
\hline 9 & Michaelis-Menten & One-compartment & Transit-compartment & NA & Proportional & $87.40^{\mathrm{a}}$ & $109.40^{\mathrm{a}}$ & $127.12^{\circ}$ \\
\hline 10 & Michaelis-Menten & Two-compartment & First-order with no delay & NA & Proportional & $89.24^{\mathrm{a}}$ & $111.24^{\mathrm{a}}$ & $128.96^{\circ}$ \\
\hline 11 & Michaelis-Menten & Two-compartment & First-order with lag time & NA & Proportional & $87.39^{\mathrm{a}}$ & $113.39^{\mathrm{a}}$ & $134.33^{\circ}$ \\
\hline 12 & Michaelis-Menten & Two-compartment & Transit-compartment & NA & Proportional & $86.67^{\mathrm{a}}$ & $116.67^{\mathrm{a}}$ & 140.84 \\
\hline 13 & Michaelis-Menten & One-compartment & First-order with no delay & Winter-Tozer & Proportional & 244.00 & 264.00 & 280.11 \\
\hline 14 & Michaelis-Menten & One-compartment & First-order with no delay & Linear binding & Proportional & 259.54 & 279.54 & 295.65 \\
\hline 15 & Michaelis-Menten & One-compartment & First-order with no delay & $\begin{array}{l}\text { Non-linear single-bind- } \\
\text { ing site }\end{array}$ & Proportional & 258.31 & 282.31 & 301.64 \\
\hline 16 & Michaelis-Menten & One-compartment & First-order with no delay & $\begin{array}{l}\text { Non-linear multiple- } \\
\text { binding site }\end{array}$ & Proportional & 256.21 & 280.21 & 299.54 \\
\hline 17 & Michaelis-Menten & One-compartment & First-order with no delay & Winter-Tozer & Combined 1 & $238.02^{\mathrm{a}}$ & $264.02^{\mathrm{a}}$ & $284.96^{\circ}$ \\
\hline 18 & Michaelis-Menten & One-compartment & First-order with no delay & Linear binding & Combined 1 & $262.07^{\mathrm{a}}$ & $286.07^{\mathrm{a}}$ & $305.41^{\circ}$ \\
\hline 19 & Michaelis-Menten & One-compartment & First-order with no delay & $\begin{array}{l}\text { Non-linear single-bind- } \\
\text { ing site }\end{array}$ & Combined 1 & $253.33^{\mathrm{a}}$ & $281.33^{\mathrm{a}}$ & $303.88^{\circ}$ \\
\hline 20 & Michaelis-Menten & One-compartment & First-order with no delay & $\begin{array}{l}\text { Non-linear multiple- } \\
\text { binding site }\end{array}$ & Combined 1 & $254.20^{\mathrm{a}}$ & $282.20^{\mathrm{a}}$ & $304.75^{\circ}$ \\
\hline 21 & Michaelis-Menten & One-compartment & First-order with no delay & Winter-Tozer & Combined 2 & $242.40^{\mathrm{a}}$ & $268.40^{\mathrm{a}}$ & 289.34 \\
\hline 22 & Michaelis-Menten & One-compartment & First-order with no delay & Linear binding & Combined 2 & $263.18^{\mathrm{a}}$ & $287.18^{\mathrm{a}}$ & $306.51^{\circ}$ \\
\hline 23 & Michaelis-Menten & One-compartment & First-order with no delay & $\begin{array}{l}\text { Non-linear single-bind- } \\
\text { ing site }\end{array}$ & Combined 2 & $254.96^{\mathrm{a}}$ & $282.96^{\mathrm{a}}$ & $305.51^{\circ}$ \\
\hline 24 & Michaelis-Menten & One-compartment & First-order with no delay & $\begin{array}{l}\text { Non-linear multiple- } \\
\text { binding site }\end{array}$ & Combined 2 & $260.93^{\mathrm{a}}$ & $288.93^{\mathrm{a}}$ & $311.48^{\circ}$ \\
\hline 25 & Michaelis-Menten & One-compartment & First-order with no delay & Winter-Tozer & Constant & 245.84 & 267.84 & 285.56 \\
\hline 26 & Michaelis-Menten & One-compartment & First-order with no delay & Linear binding & Constant & 260.23 & 280.23 & 296.34 \\
\hline 27 & Michaelis-Menten & One-compartment & First-order with no delay & $\begin{array}{l}\text { Non-linear single-bind- } \\
\text { ing site }\end{array}$ & Constant & $257.24^{\mathrm{a}}$ & $281.24^{\mathrm{a}}$ & $300.58^{\circ}$ \\
\hline 28 & Michaelis-Menten & One-compartment & First-order with no delay & $\begin{array}{l}\text { Non-linear multiple- } \\
\text { binding site }\end{array}$ & Constant & $258.35^{\mathrm{a}}$ & $282.35^{\mathrm{a}}$ & 301.68 \\
\hline
\end{tabular}

AIC Akaike information criterion, BIC Bayesian information criterion, NA not applicable, $O F V$ objective function value

${ }^{a}$ The fisher information matrix was not correctly estimated (i.e., the models failed to converge using stochastic approximation expectation-maximization algorithm)

The structural model (i.e., model 7 in Table 2) was parameterized as bioavailability $(F)$, absorption rate constant $\left(k_{\mathrm{a}}, \mathrm{h}^{-1}\right)$, volume of distribution $\left(V_{\mathrm{d}}, \mathrm{L}\right)$, maximal elimination rate $\left(V_{\max }, \mathrm{mg} / \mathrm{h}\right)$, and Michaelis-Menten constant (i.e., free phenytoin concentration at which the elimination rate reaches $50 \%$ of $\left.V_{\max }\right)\left(K_{\mathrm{m}}, \mathrm{mg} / \mathrm{L}\right)$. Moreover, additional parameters tailored to each protein-binding model were considered: CF for the Winter-Tozer model (model 13 ); $K_{\mathrm{b}}$ for the linear binding model (model 14); and $B_{\max }$ and $K_{\mathrm{D}}$ for the non-linear binding models (models 15 and 16). Neither $F$ nor $k_{\text {a }}$ could be precisely estimated in our dataset because of the limited sample size, and these values were fixed to 0.859 and $0.225 \mathrm{~h}^{-1}$, respectively (e.g., $\left.[24,45]\right)$. To obtain biologically reasonable parameter estimates, $V_{\max }$ and $\mathrm{Km}$ were initially fixed to $25 \pm 0.2 \mathrm{mg} / \mathrm{h}$ and $0.5 \pm 0.1 \mathrm{mg} / \mathrm{L}$, respectively, using reference data collected in prior studies $[26,44]$. Because of the computational complexity of the 


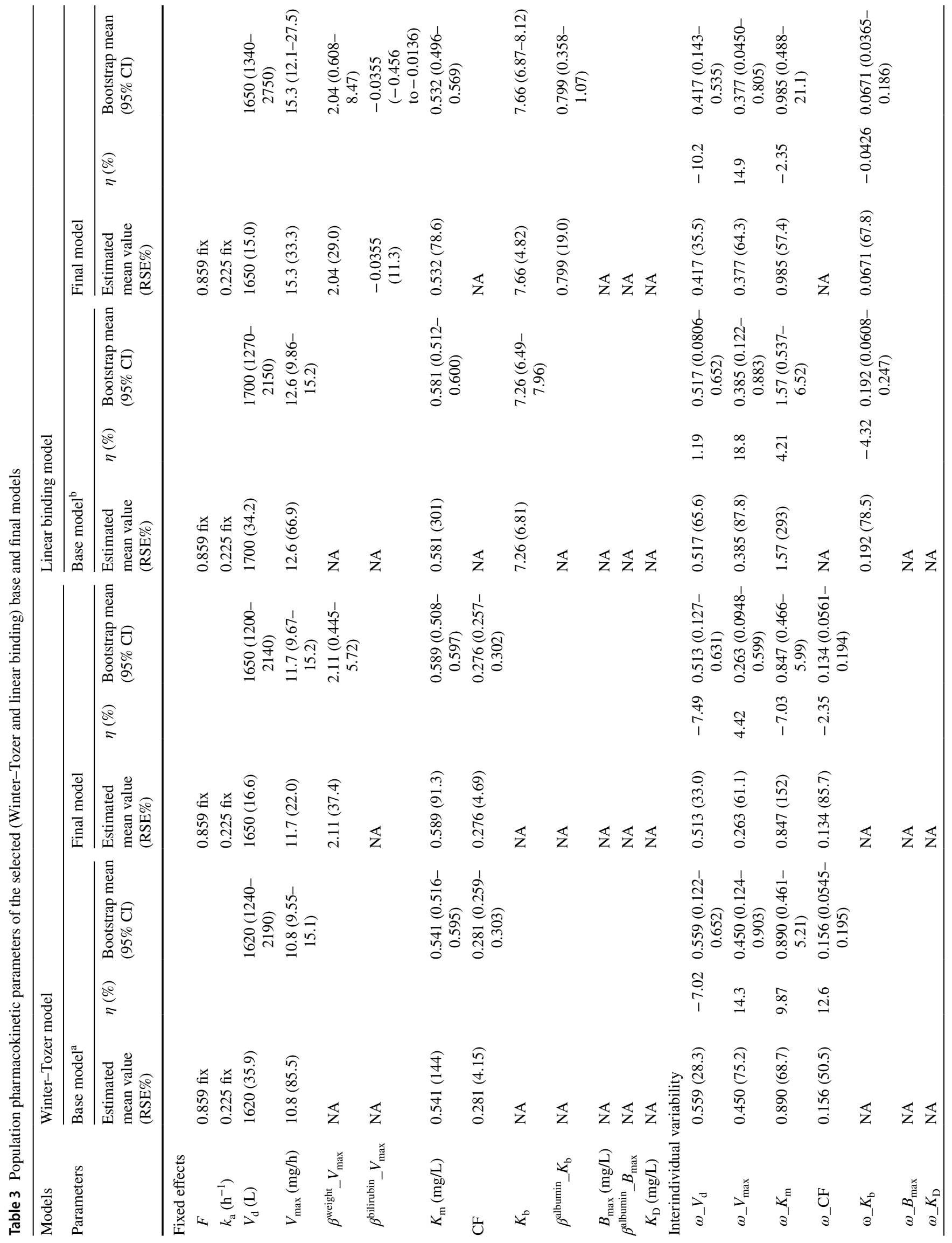




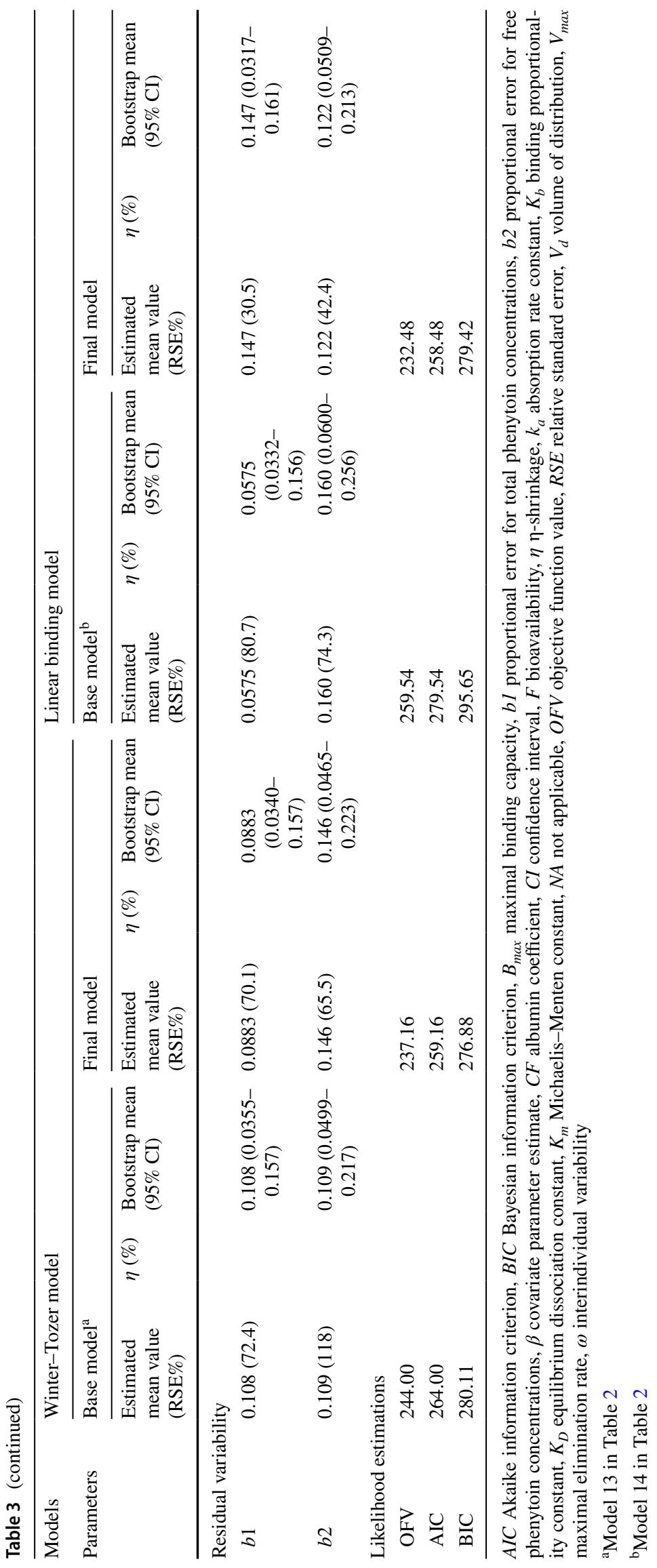


non-linear multiple-binding-site model, two $K_{\mathrm{D}}$ values were also fixed to 38.8 and $24.3 \mathrm{mg} / \mathrm{L}$ [30].

\subsection{Covariate Model Selection}

Covariate analyses were conducted on all four protein-binding models. For the linear binding model, log-transformed weight (positive relationship) and total bilirubin (negative relationship) independently affected $V_{\max }$, whereas logtransformed albumin positively affected $K_{\mathrm{b}}$. The inclusion of these covariates reduced the overall OFV by 27.06 compared with the base model. OFV was increased by 14.08 $(p<0.001), 6.21(p<0.05)$, and $6.77(p<0.01)$ when albumin, weight, and total bilirubin were sequentially eliminated. $V_{\max }$ and $K_{\mathrm{b}}$ can be estimated as follows:

$\log \left(V \max _{j}\right)=2.73+2.04 \times \log \left(\frac{\text { weight }_{j}}{70}\right)-0.0355 \times$ bilirubin $_{j}+\eta_{j}$

$\log \left(K \mathrm{~b}_{j}\right)=2.04+0.799 \times \log \left(\frac{\text { albumin }_{j}}{2.7}\right)+\eta_{j}$

where $V \max _{j}$ and $K \mathrm{~b}_{j}$ are the estimated $V_{\max }$ and $K_{\mathrm{b}}$ of the $j$ th individual with weight ${ }_{j}(\mathrm{~kg})$, bilirubin $_{j}(\mu \mathrm{mol} / \mathrm{L})$, and albumin $_{j}(\mathrm{~g} / \mathrm{dL}) . \eta_{j}$ represents the random effects of the $j$ th individual. The results of covariate analyses conducted on other protein-binding models are provided in ESM 1 [21-23].

\subsection{Final Model}

The population pharmacokinetic parameters from each model are summarized in Tables 3 and 4. Significantly higher OFV, AIC, and BIC values observed in the final non-linear multiple-binding site model indicated poor fitting. AIC and BIC were comparable in other protein-binding models, but the linear binding model showed significantly lower OFV $(\triangle \mathrm{OFV}=-4.68, p<0.05)$ than the Winter-Tozer model and relatively smaller RSEs in fixed-effects estimates compared with the non-linear single-binding-site model. Overall assessments of likelihood estimations, physiological relevance, and RSEs indicated that the linear binding model best described the protein binding of phenytoin in this adult population (please see Sect. 4). This result is supported by the linear relationship between actual free and total phenytoin concentrations $\left(R^{2}=0.95, p<0.0001\right.$; Fig. 1). Figure 2 represents the final structural model incorporating the linear binding model.

\subsection{Model Evaluation}

Diagnostic plots for the final model with linear protein binding are shown in Figs. 3, 4, 5. The plots of observed free plasma concentrations versus population- or individual-predicted free concentrations showed uniformly scattered data along the line of identity, indicating the lack of significant bias and relatively good precision (Fig. 3) [40, 46]. Except for slight positive bias, the data generally centered around the line of zero identity without major systematic bias in the population- and individual-weighted residual plots of free phenytoin (Fig. 4), confirming the lack of obvious defects in the structural (Fig. 4a,c) and error (Fig. 4b,d) models [46]. The pcVPC plot of free phenytoin (Fig. 5) indicated the lack of apparent model misspecifications [40, 46], and all population parameter estimates were within the $95 \%$ confidence interval generated by bootstrap analysis (Table 3), verifying the robustness of the final model $[40,46]$. The $\eta$-shrinkage values were $<15 \%$ in the final linear binding model (Table 3), confirming adequate model parameterization $[46,47]$.

\section{Discussion}

Therapeutic drug monitoring of phenytoin is typically conducted by measuring total concentrations, whereas free concentrations are usually estimated with predictive equations $[13,18]$. The original Winter-Tozer equation provided reliable estimations of free phenytoin for patients with normal serum albumin [19] but exhibited bias and imprecision in patients with compromised renal function or hypoalbuminemia [48]. Modified Winter-Tozer equations with revised albumin coefficients have been proposed to improve predictability in various patient populations [20-23]. Population pharmacokinetic modeling has also been used to characterize the binding of phenytoin, with apparently improved prediction of free concentrations compared with the original Winter-Tozer equation. Hennig et al. [24] utilized a linear partition coefficient for protein binding and reported enhanced predictive performance in critically ill children. ter Heine et al. [25] used a non-linear single-sitespecific binding model and also found increased accuracy and precision in a variety of patient populations. In addition, clinical covariates influencing the free fraction or binding of phenytoin have been reported in a patient cohort with a large age distribution (e.g., albumin, severe renal dysfunction, valproic acid) [25], in adult patients with cancer (e.g., albumin, carbamazepine, valproic acid) [26], in pediatric patients (e.g., albumin, serum urea, valproic acid) [27], and in critically ill children (e.g., albumin) [24] using non-linear mixed-effects modeling. Based on these findings, it remains equivocal which binding model best described the interaction between phenytoin and albumin and whether additional covariates can influence the binding process.

A one-compartment, first-order absorption, and Michaelis-Menten elimination structural model provided the best 


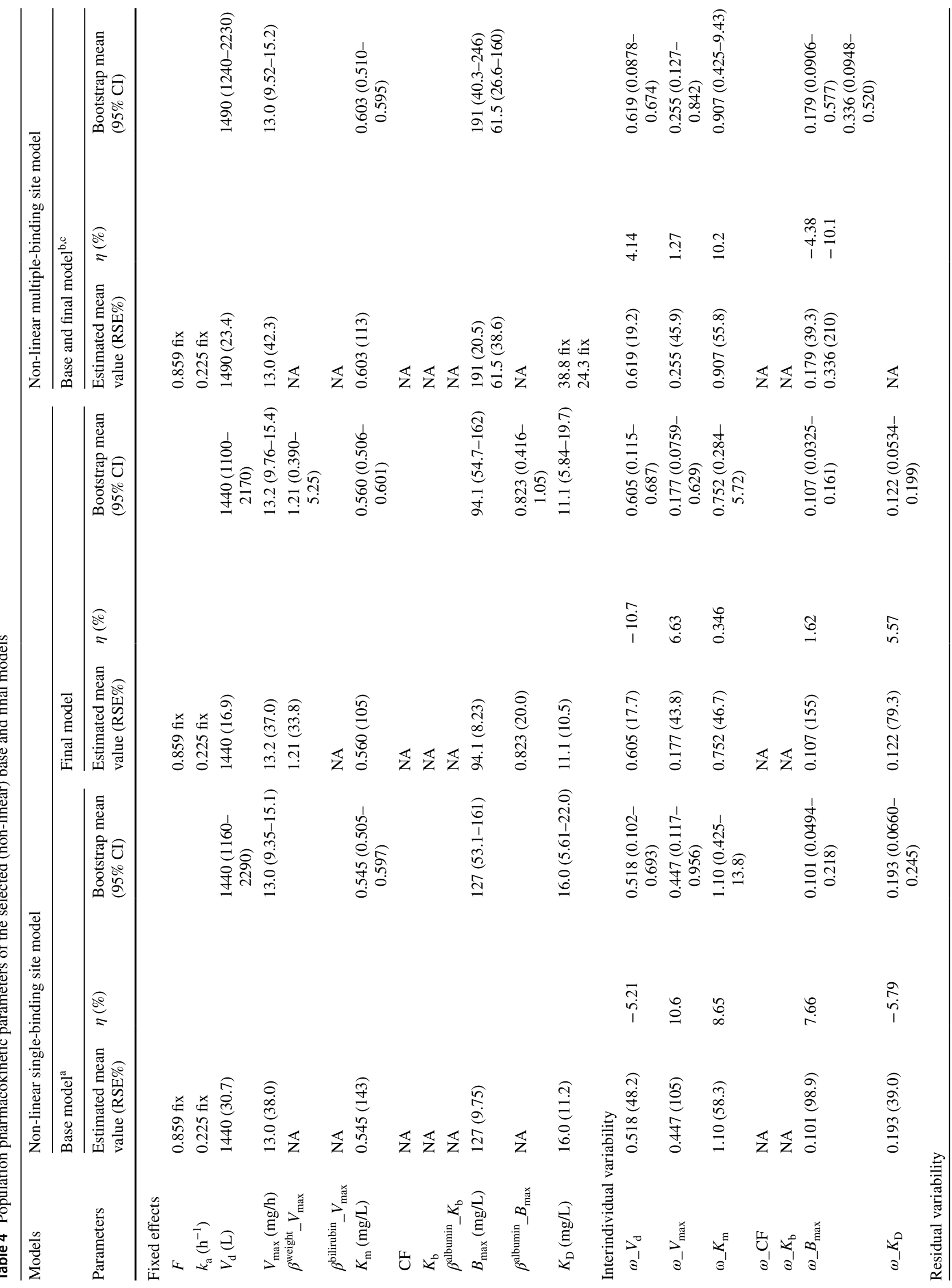




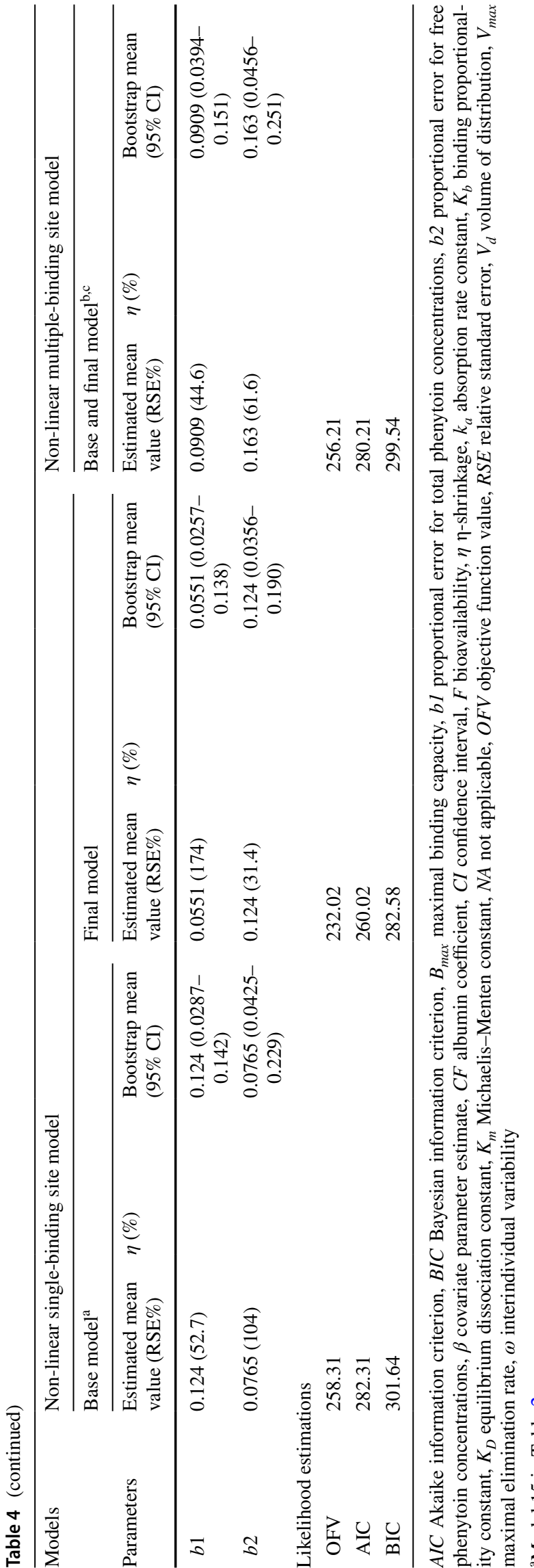

fit for free phenytoin pharmacokinetic profiles in our dataset. Although the majority of the population pharmacokinetic studies for phenytoin have only focused on estimating $V_{\max }$ and $K_{\mathrm{m}}$ without providing additional structural components (e.g., $[44,49,50]$ ), our findings are consistent with those that have employed the one-compartment (e.g., [24, 51-53]) and first-order absorption models (e.g., [24, 51, 52]). However, because insufficient data were collected during early postdose periods in our study, it was not possible to precisely estimate the absorption process in our model; therefore, the bioavailability and absorption rate constant values had to be fixed to literature data (e.g., [24, 45]). This is a general limitation for other published phenytoin models (e.g., [24, 51, 53]). Moreover, phenytoin clearance was described by Michaelis-Menten kinetics in our model, which is consistent with capacity-limiting metabolism at therapeutic concentrations of phenytoin $[4,6]$ demonstrated in the literature (e.g., $[44,49,50,54,55])$. The only exception to our knowledge is Hennig et al. [24] who used a linear elimination model in critically ill children, possibly because of increased $\mathrm{Km}$ values in their patients with head trauma [56]. The population pharmacokinetic parameter estimates for $K_{\mathrm{m}}(0.532 \mathrm{mg} / \mathrm{L}$; Table 3$)$ and $V_{\max }(5.36 \mathrm{mg} / \mathrm{day} / \mathrm{kg}$; converted from data presented in Table 3) obtained in the final linear binding model were generally in agreement with reported ranges (i.e., $0.40-0.73 \mathrm{mg} / \mathrm{L}$ and $7.9-9.1 \mathrm{mg} / \mathrm{day} / \mathrm{kg}$, respectively $[26,44])$ for free phenytoin. However, the estimated $V_{\mathrm{d}}$ for free phenytoin in our model $(24.1 \mathrm{~L} / \mathrm{kg}$; converted from data presented in Table 3) was larger than previously reported in adult patients with cancer $(0.15 \mathrm{~L} / \mathrm{kg})$ [26] and children $(6.39 \mathrm{~L} / \mathrm{kg})$ [24]. Given the lipophilic nature of phenytoin [57], this observation may be attributed to decreased fat tissue distribution in these patient groups [58, 59].

Four protein-binding models were directly compared in this study. The CF of the Winter-Tozer model was estimated to be 0.276 (Table 3), which is consistent with the coefficients reported by Anderson et al. [21] (0.25, hypoalbuminemia), Cheng et al. [22] (0.275, hypoalbuminemia), and Kane et al. [23] (0.29, neurosurgical intensive care) but inconsistent with Soriano et al. [20] (0.20, severe renal impairment with a different assay temperature) and the ฐoriginal Winter-Tozer equation (0.20, normal albumin) [19]. This observation might be explained by similarities of o our patient population (i.e. with [21-23]), where the majority of subjects $(94.6 \%)$ had mild hypoalbuminemia (i.e., a albumin $<3.5 \mathrm{~g} / \mathrm{dL}$ ), and a substantial portion $(43.2 \%)$ was admitted to critical care wards (Table 1). The Winter-Tozer model was not the optimal protein-binding model in this study possibly because it was originally developed with the assumptions of a normal phenytoin free fraction of $10 \%$ and serum albumin of $4.4 \mathrm{~g} / \mathrm{dL}$ [19]. However, as evident by Cheng et al. [22], optimizing the albumin coefficient of the Winter-Tozer equation alone did not fully improve the 


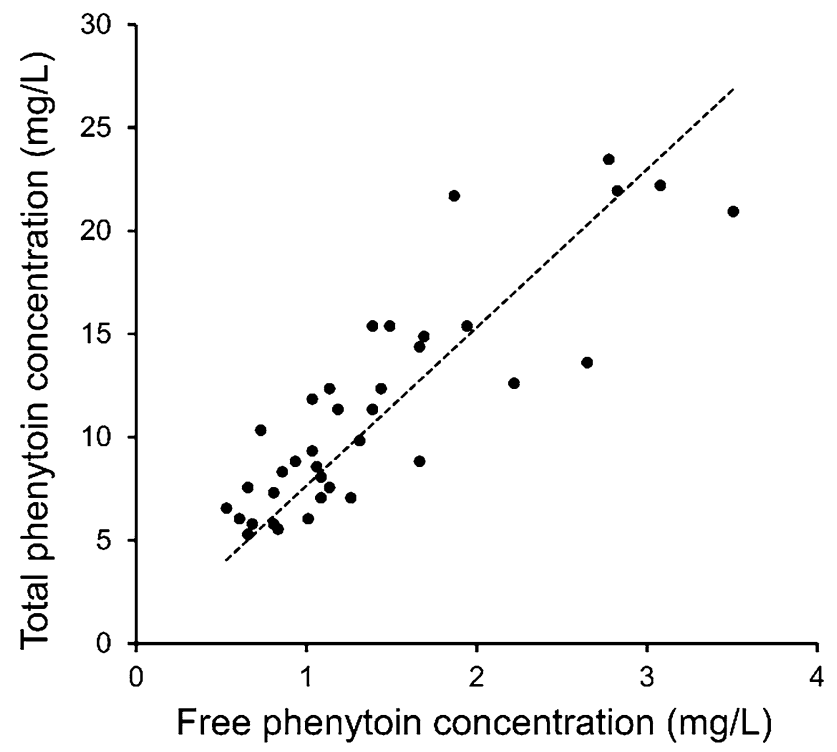

Fig. 1 Linear correlation between actual free and total phenytoin concentrations observed in 37 subjects

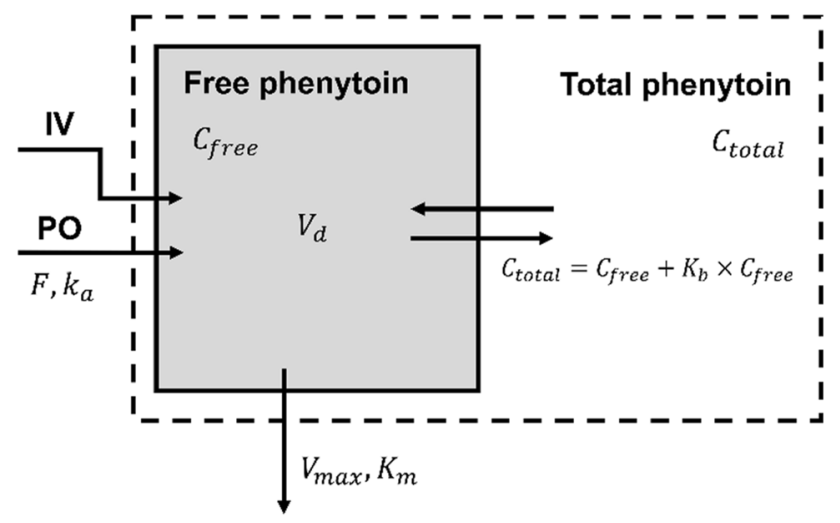

Fig. 2 Final population pharmacokinetic structural model of phenytoin incorporating the linear binding model. $C_{\text {free }}$ free phenytoin concentration, $C_{\text {total }}$ total phenytoin concentration, $F$ bioavailability, $I V$ intravenous, $k_{\mathrm{a}}$ absorption rate constant, $K_{\mathrm{b}}$ binding proportionality constant, $K_{\mathrm{m}}$ Michaelis-Menten constant, $P O$ oral, $V_{\mathrm{d}}$ volume of distribution, $V_{\max }$ maximal elimination rate

accuracy and precision of the prediction, indicating additional limitations of the model.

The non-linear single-binding-site model also adequately described phenytoin binding, but it generated relatively larger RSEs in fixed-effects estimates, possibly because only the non-saturable portion of the non-linear binding model was used in our dataset. This is evident mathematically, where the estimated $K_{\mathrm{D}}$ value $(11.1 \mathrm{mg} / \mathrm{L})$ was larger than the free phenytoin concentrations observed in our subjects $(1.4 \pm 0.7 \mathrm{mg} / \mathrm{L})$. In this scenario, Eq. (3) (i.e., the non-linear binding model) can be simplified as follows:
$C_{\text {total }}=C_{\text {free }}+\frac{B_{\mathrm{max}}}{K_{D}} \times C_{\text {free }}$

Equation (7) is essentially a linear binding model (Eq. 2) where $K_{\mathrm{b}}$ is characterized as $B_{\text {max }} / K_{\mathrm{D}}$, suggesting that the linear binding model provides a more precise and "parsimonious" characterization of phenytoin binding at the typical free concentrations observed clinically. On the other hand, in patients exhibiting relatively high concentrations of free phenytoin, the non-linear single-bindingsite model may be more suitable. This observation may also explain the discrepancy in the protein-binding models utilized by Hennig et al. [24] (i.e., linear binding model) and ter Heine et al. [25] (i.e., non-linear binding model), where the documented free phenytoin concentrations were relatively low $(0.88 \pm 0.79 \mathrm{mg} / \mathrm{L}$ ) and high (up to $\sim 9 \mathrm{mg} / \mathrm{L}$ reported in the study), respectively. Moreover, the $B_{\max }$ value $(94.1 \mathrm{mg} / \mathrm{L}$ [RSE $8.23 \%]$ ) in our non-linear single-bindingsite model was lower than that reported in ter Heine et al. [25] (117 mg/L [14\%]). The discrepancy may be attributed to the mild hypoalbuminemia observed in the majority of our patients. Supporting this observation, covariate analysis identified albumin as a positive modulator of $B_{\max }$ in our non-linear single-binding-site model, although the interindividual variability of $B_{\max }$ and its RSE was not improved with the inclusion of albumin ( Table 4). On the other hand, the non-linear multiple-binding-site model was the worst performing of the four binding models, possibly because of over parametrization in the setting of a relatively small number of subjects and that phenytoin may only bind to a single site on albumin (discussed below in Sect. 4).

Overall, our analysis indicated that the linear binding model provided the best description of phenytoin-albumin binding in this patient population (i.e., better diagnostics, improved RSE values for fixed-effects estimates, physiological relevance, and reduced parametrization). In the linear binding model, the relationship between $K_{\mathrm{b}}\left(C_{\text {bound }} / C_{\text {free }}\right)$ and free fraction $\left(f_{\mathrm{u}}, C_{\text {free }} / C_{\text {total }}\right)$ can be expressed as follows:

$K_{\mathrm{b}}=\frac{1}{f_{\mathrm{u}}}-1$

The estimated $K_{\mathrm{b}}$ was 7.66 (Table 3 ) in this study population, with a median $f_{\mathrm{u}}$ of 0.118 (Table 1 ). As phenytoin is extensively bound to albumin $(\sim 90 \%)[5,13]$, reduced albumin concentrations can decrease the percentage of bound phenytoin, followed by decreased $K_{\mathrm{b}}$ and increased $f_{\mathrm{u}}$. This observation is consistent with that demonstrated by several investigators [24, 26, 27]. In the clinic, reduced albumin concentration leading to increased free fraction may result in reduced total phenytoin concentration, which should be interpreted with caution because the free, pharmacologically active concentration would, in theory, remain the same. In 


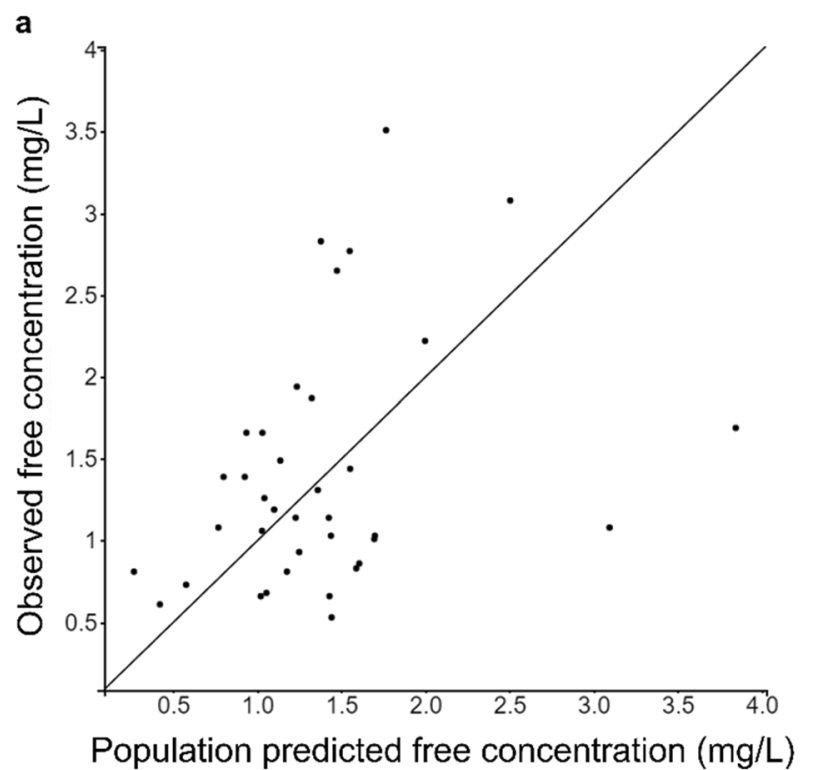

Fig. 3 a Observed plasma concentration of free phenytoin vs. population predicted free concentration; $\mathbf{b}$ observed plasma concentration of free phenytoin vs. individual-predicted free concentration in the final

concordance with this, the inclusion of albumin further reduced both the RSE (from 6.81 to $4.82 \%$ ) and the interindividual variability (from 19.2 to $6.71 \%$ ) of $\mathrm{K}_{\mathrm{b}}$ in the final model compared with the base model (Table 3 ). In general, linear binding models are typically supported by high binding capacities [60], as evident in our model, with a relatively high $B_{\max }$ of $373 \mu \mathrm{M}$ (i.e., based on estimates obtained in the non-linear single-binding-site model; converted to molar units; Table 4). Maximal binding capacity is in turn reflective of the concentration of the binding protein (i.e., albumin) and the number of available binding sites [61]. As the average albumin concentration in our sample population was $397 \mu \mathrm{M}$ (converted to molar units; Table 1), it may be reasoned that the number of phenytoin binding sites on albumin would be $\sim 0.940$ (i.e., $373 \mu \mathrm{M} / 391 \mu \mathrm{M}$ ). This provides indirect evidence that phenytoin might be primarily bound to only one site on albumin in the clinical setting, which is inconsistent with Chen et al. [30], who suggested the presence of two binding sites using an in vitro model. Further investigations are required to determine the clinical relevance of this information.

In the linear binding model, weight and total bilirubin independently influenced $V_{\max }$. Weight was positively associated with $V_{\max }$ (Table 3, Eq. 5), an effect also observed in studies that estimated $V_{\max }$ based on the total concentration $[52,53]$. Furthermore, increased total bilirubin concentration (representative of compromised hepatic excretory function) was correlated with decreased $V_{\max }$, which may be attributed to intrahepatic accumulation of toxic biliary substances, potentially leading to the impairment of hepatic

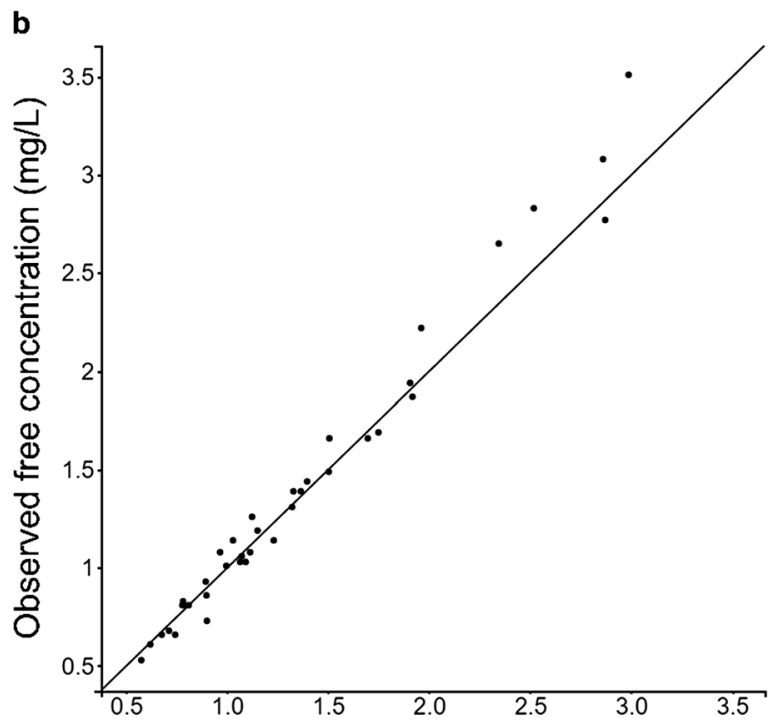

Individual predicted free concentration $(\mathrm{mg} / \mathrm{L})$

population pharmacokinetic structural model of phenytoin incorporating the linear binding model

metabolism [62]. On the other hand, clinical factors such as renal function and co-medications were not found to be significant covariates in this dataset. Uremic toxins accumulated in end-stage renal disease may alter protein binding $[63,64]$ and reduce the intrinsic clearance of phenytoin [65]; however, renal function (measured by $\mathrm{SCr}$ ) was not identified as a significant covariate in this study, possibly because only a small number of patients had severe renal disease (i.e., GFR $<30 \mathrm{~mL} / \mathrm{min} / 1.73 \mathrm{~m}^{2}$ ). Furthermore, concomitant low-dose aspirin did not impact phenytoin binding in this study, presumably because aspirin's effect is only evident at relatively higher doses [66]. Carbamazepine, heparin, phenobarbital, sulfonamides, valproic acid, and warfarin also did not affect the pharmacokinetics of phenytoin despite known interacting mechanisms [38, 67-69], which may likely be because of the insufficient study sample size (Table 1).

Despite successfully identifying the optimal phenytoin protein-binding model within a fully developed population pharmacokinetic model, this study has the following limitations. The developed linear binding model can only be applied to patients who have plasma free phenytoin concentrations much less than $11.1 \mathrm{mg} / \mathrm{L}$ (i.e., $C_{\text {free }}<<K_{\mathrm{D}}$ ), where the assumption of linearity is still valid. Further validations are also required to ensure the applicability of our model in patient populations with different degrees of hypoalbuminemia, renal dysfunction, or concurrent proteinbinding-displacing drugs, as these variables were not characterized systematically in this study. As the study was conducted retrospectively, data on patient ethnicity and genetic 

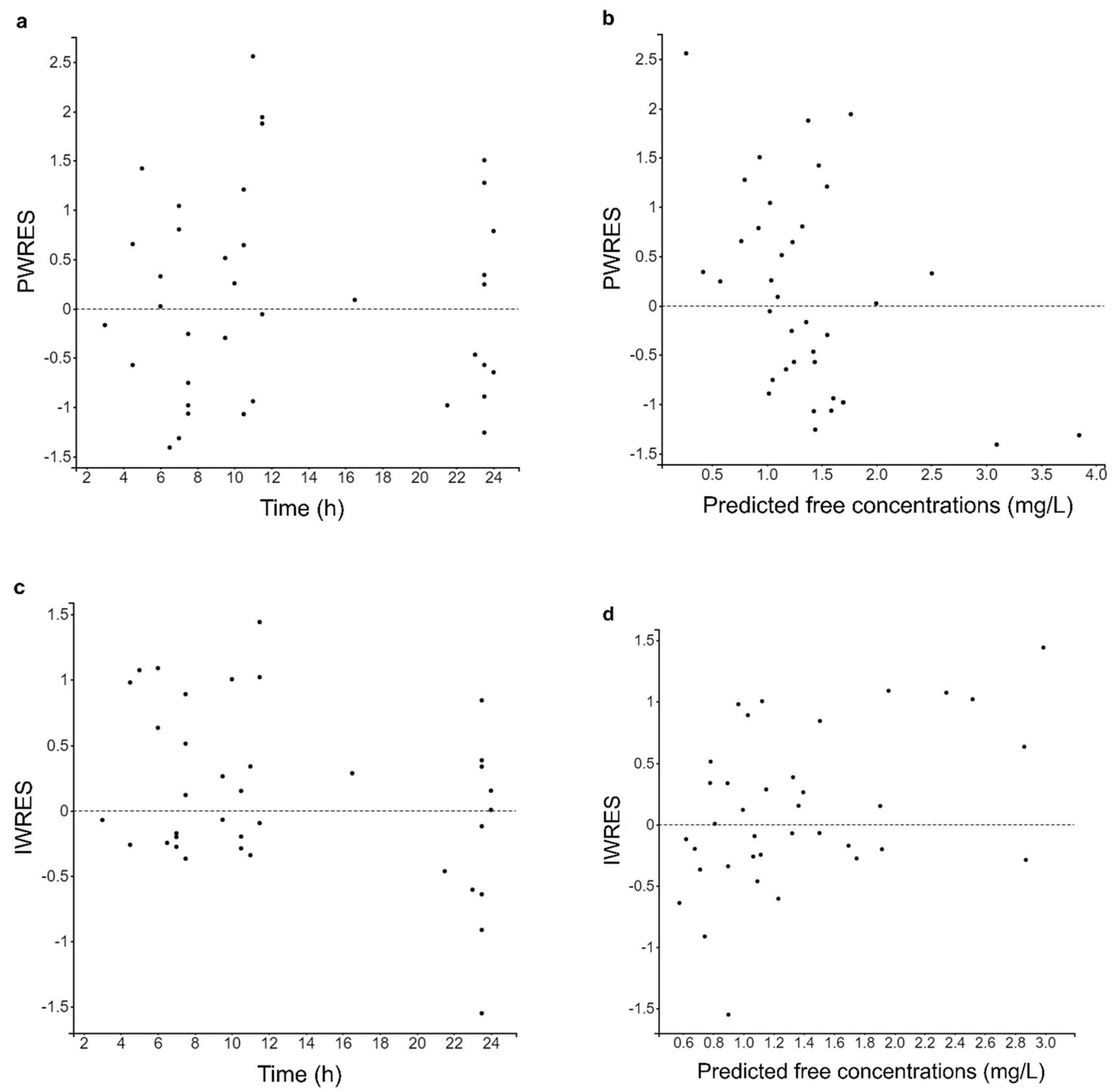

Fig. 4 a Population-weighted residuals of free phenytoin (PWRES) vs. time; b PWRES vs. predicted plasma concentration of free phenytoin; $\mathbf{c}$ Individual-weighted residuals of free phenytoin (IWRES) vs.

polymorphisms (e.g., CYP2C9*3) were not available. Ethnic variations in minor allele frequencies have been reported for CYP2C9 [70], and these polymorphic alleles have been associated with reduced metabolism [71-73] and increased adverse effects of phenytoin [74-76]. Although polymorphic forms of albumin may exhibit altered binding affinity [77], the pharmacogenomics of phenytoin binding was not characterized in this study. Finally, there may be additional binding models that were not investigated in this study.

time; and $\mathbf{d}$ IWRES vs. predicted plasma concentration of free phenytoin in the final population pharmacokinetic structural model of phenytoin incorporating the linear binding model

\section{Conclusion}

Systematic comparisons of four common protein-binding models describing the relationships between free and total phenytoin have been conducted using non-linear mixedeffects modeling. We report the novel finding that the linear binding model best characterized phenytoin binding under typical clinical conditions in a process affected by albumin concentration. In patients with higher phenytoin 
Fig. 5 Prediction-corrected visual predictive check for free phenytoin based on 1000 simulations in the final population pharmacokinetic structural model incorporating the linear binding model. Individual plasma concentrations of free phenytoin $(\cdot) ; 5$ th, median, and 95th empirical percentiles of plasma concentrations of free phenytoin (-); 5th and 95th percentiles (blue) or median (pink) prediction interval areas

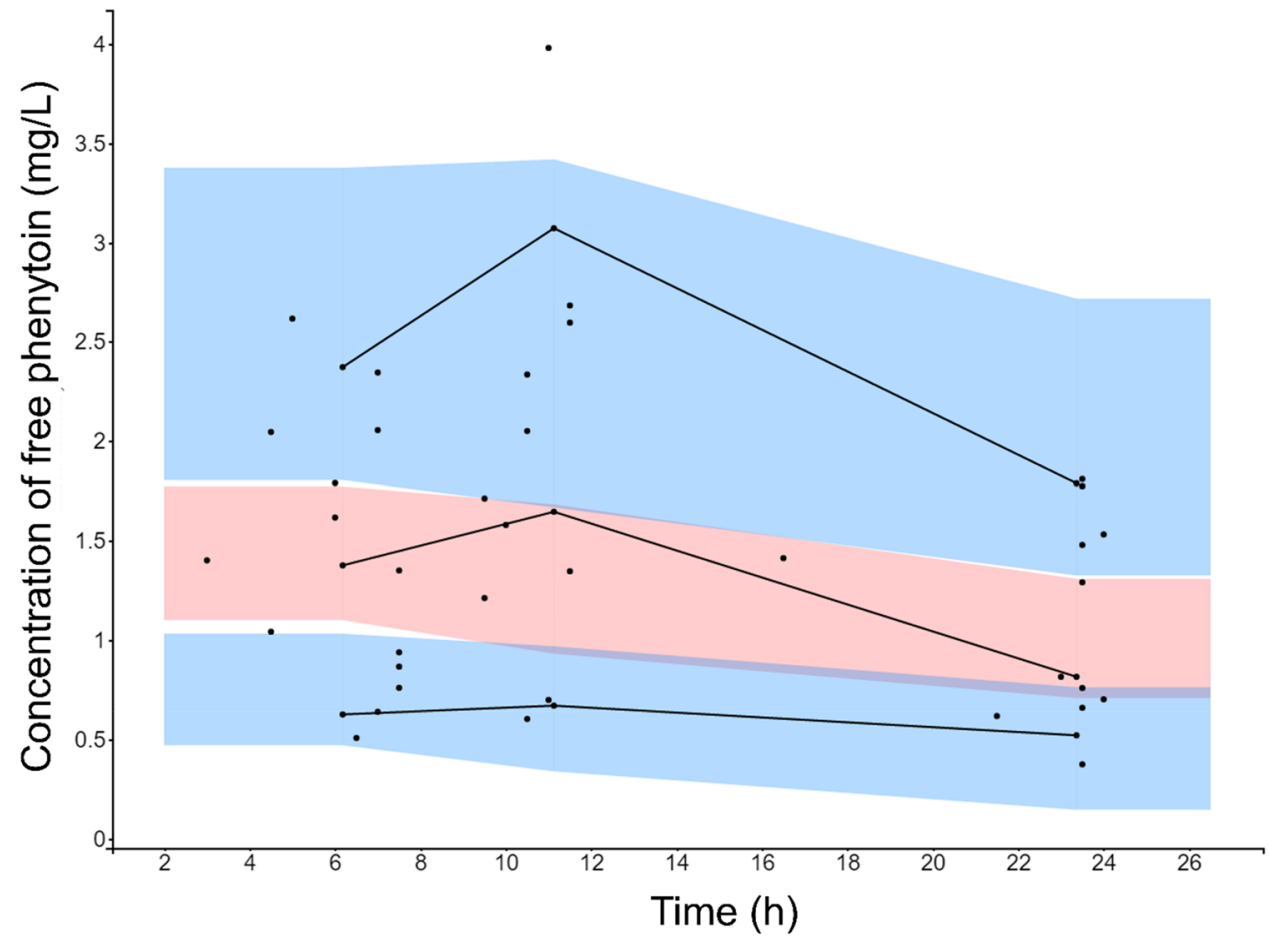

concentrations, the non-linear single-binding-site model might be more suitable. Further validations are required to determine the predictive performances of these models for the estimation of free phenytoin concentrations in the clinical setting.

\section{Declarations}

Funding Heajin Jun was supported by the International Research \& Development Program of the National Research Foundation of Korea (Ministry of Science and ICT grant \#2019K1A3A1A73079569) and a MITACS Globalink Research Grant (\#FR41232) awarded to Heajin Jun and Tony KL Kiang.

Conflicts of interest Heajin Jun, Yan Rong, Catharina Yih, Jordan Ho, Wendy Cheng, and Tony KL Kiang have no conflicts of interest that are directly relevant to the content of this article.

Availability of data and material Reasonable requests to access the data should be directed to the corresponding author (Tony KL Kiang, tkiang@ualberta.ca).

Code availability MonolixSuite-2019R2 (Lixoft SAS, Antony, France) and Rsmlx package (Rsmlx, version 2.0.2, Xpop Inria Team) R software v3.6.3 (R Core Team, Vienna, Austria) were used. Requests to access the custom codes for protein-binding models should be directed to the corresponding author (Tony KL Kiang, tkiang@ualberta.ca).

Ethics approval The study protocol was approved by the University of British Columbia (H18-02215) and the University of Alberta (Pro00100357) research ethics boards. The study was performed in accordance with all ethical standards outlined in the 1964 Declaration of Helsinki and its later amendments.
Consent As this was a retrospective study, neither consent to participate nor consent to publish were required.

Author contributions Wendy Cheng and Tony Kiang conceived the original study design. Retrospective data collection was conducted by Jordan Ho as part of his pharmacy residency project (supervised by Wendy Cheng [primary mentor], Catharina Yih, and Tony Kiang). Non-linear mixed-effects modeling was conducted by Heajin Jun, Yan Rong, and Tony Kiang. The manuscript was drafted by Heajin Jun and Tony Kiang. All listed authors provided feedback and commentary on the submitted draft.

Open Access This article is licensed under a Creative Commons Attribution-NonCommercial 4.0 International License, which permits any non-commercial use, sharing, adaptation, distribution and reproduction in any medium or format, as long as you give appropriate credit to the original author(s) and the source, provide a link to the Creative Commons licence, and indicate if changes were made. The images or other third party material in this article are included in the article's Creative Commons licence, unless indicated otherwise in a credit line to the material. If material is not included in the article's Creative Commons licence and your intended use is not permitted by statutory regulation or exceeds the permitted use, you will need to obtain permission directly from the copyright holder. To view a copy of this licence, visit http://creativecommons.org/licenses/by-nc/4.0/.

\section{References}

1. French JA, Gazzola DM. New generation antiepileptic drugs: what do they offer in terms of improved tolerability and safety? Ther Adv Drug Saf. 2011;2:141-58.

2. Abou-Khalil BW. Update on antiepileptic drugs 2019. Continuum (Minneap Minn). 2019;25:508-36. 
3. Phenytoin: Drug Usage Statistics, United States, 2007-2017. ClinCalc. 2017. https://clincalc.com/DrugStats/Drugs/Phenytoin. Accessed 12 Jul 2020.

4. Morita DA, Glauser TA. Phenytoin and Fosphenytoin. In: Wyllie E, Cascino GD, Gidal BE, Goodkin HP, editors. Wyllie's treatment of epilepsy. 5 ed. Philadelphia: Wolters Kluwer, Lippincott Williams \& Wilkins; 2011. pp. 630-647.

5. Richens A. Clinical pharmacokinetics of phenytoin. Clin Pharmacokinet. 1979;4:153-69.

6. Bajpai M, Roskos LK, Shen DD, Levy RH. Roles of cytochrome P4502C9 and cytochrome P4502C19 in the stereoselective metabolism of phenytoin to its major metabolite. Drug Metab Dispos. 1996;24:1401-3.

7. Veronese ME, Mackenzie PI, Doecke CJ, McManus ME, Miners JO, Birkett DJ. Tolbutamide and phenytoin hydroxylations by cDNA-expressed human liver cytochrome P4502C9. Biochem Biophys Res Commun. 1991;175:1112-8.

8. Doecke CJ, Veronese ME, Pond SM, Miners JO, Birkett DJ, Sansom LN, McManus ME. Relationship between phenytoin and tolbutamide hydroxylations in human liver microsomes. Br J Clin Pharmacol. 1991;31:125-30.

9. Kozelka FL, Hine CH. Degradation products of dilantin. J Pharmacol Exp Ther. 1943;77:175-9.

10. Gerber N, Wagner JG. Explanation of dose-dependent decline of diphenylhydantoin plasma levels by fitting to the integrated form of the Michaelis-Menten equation. Res Commun Chem Pathol Pharmacol. 1972;3:455-66.

11. Brodie MJ, Mintzer S, Pack AM, Gidal BE, Vecht CJ, Schmidt D. Enzyme induction with antiepileptic drugs: cause for concern? Epilepsia. 2013;54:11-27.

12. Marvanova M. Pharmacokinetic characteristics of antiepileptic drugs (AEDs). Ment Health Clin. 2016;6:8-20.

13. Phenytoin/fosphenytoin. In: Bauer LA, editor. Applied clinical pharmacokinetics. 3 ed. New York: McGraw-Hill; 2014.

14. Buchthal F, Svensmark O. Aspects of the pharmacology of phenytoin (Dilantin) and phenobarbital relevant to their dosage in the treatment of epilepsy. Epilepsia. 1960;1:373-84.

15. Kutt H, Winters W, Kokenge R, McDowell F. Diphenylhydantoin metabolism, blood levels, and toxicity. Arch Neurol. 1964;11:642-8.

16. Lund L. Anticonvulsant effect of diphenylhydantoin relative to plasma levels. A prospective three-year study in ambulant patients with generalized epileptic seizures. Arch Neurol. 1974;31:289-94.

17. Chetty M, Miller R, Seymour MA. Phenytoin auto-induction. Ther Drug Monit. 1998;20:60-2.

18. Krasowski MD, Penrod LE. Clinical decision support of therapeutic drug monitoring of phenytoin: measured versus adjusted phenytoin plasma concentrations. BMC Med Inform Decis Mak. 2012;12:7.

19. Tozer TN, Winter ME. Phenytoin. In: Evans WE, Schentag JJ, Jusko WJ, editors. Applied pharmacokinetics: principles of therapeutic drug monitoring. 3rd ed. Vancouver: Applied Therapeutics; 1992. p. 1-44.

20. Soriano VV, Tesoro EP, Kane SP. Characterization of free phenytoin concentrations in end-stage renal disease using the WinterTozer equation. Ann Pharmacother. 2017;51:669-74.

21. Anderson GD, Pak C, Doane KW, Griffy KG, Temkin NR, Wilensky AJ, Winn HR. Revised Winter-Tozer equation for normalized phenytoin concentrations in trauma and elderly patients with hypoalbuminemia. Ann Pharmacother. 1997;31:279-84.

22. Cheng W, Kiang TKL, Bring P, Ensom MHH. Predictive performance of the Winter-Tozer and derivative equations for estimating free phenytoin concentration. Can J Hosp Pharm. 2016;69:269-79.

23. Kane SP, Bress AP, Tesoro EP. Characterization of unbound phenytoin concentrations in neurointensive care unit patients using a revised Winter-Tozer equation. Ann Pharmacother. 2013;47:628-36.

24. Hennig S, Norris R, Tu Q, van Breda K, Riney K, Foster K, Lister B, Charles B. Population pharmacokinetics of phenytoin in critically ill children. J Clin Pharmacol. 2015;55:355-64.

25. ter Heine R, Kane SP, Huitema ADR, Krasowski MD, van Maarseveen EM. Nonlinear protein binding of phenytoin in clinical practice: development and validation of a mechanistic prediction model. Br J Clin Pharmacol. 2019;85:2360-8.

26. Joerger M, Huitema ADR, Boogerd W, van der Sande JJ, Schellens JHM, Beijnen JH. Interactions of serum albumin, valproic acid and carbamazepine with the pharmacokinetics of phenytoin in cancer patients. Basic Clin Pharmacol Toxicol. 2006;99:133-40.

27. ter Heine R, van Maarseveen EM, van der Westerlaken MML, Braun KPJ, Koudijs SM, ten Berg MJ, Malingre MM. The quantitative effect of serum albumin, serum urea, and valproic acid on unbound phenytoin concentrations in children. J Child Neurol. 2014;29:803-10.

28. Levey AS, Stevens LA, Schmid CH, Zhang YL, Castro AF, 3rd, Feldman HI, Kusek JW, Eggers P, Van Lente F, Greene T, Coresh J. A new equation to estimate glomerular filtration rate. Ann Intern Med. 2009;150:604-12.

29. Siemens Dimension Vista ${ }^{\circledR}$ System Flex ${ }^{\circledR}$ reagent cartridge: phenytoin package insert. Siemens Healthcare Diagnostics Inc. 2017. Accessed 12 Jul 2020.

30. Chen J, Ohnmacht C, Hage DS. Studies of phenytoin binding to human serum albumin by high-performance affinity chromatography. J Chromatogr B Analyt Technol Biomed Life Sci. 2004;809:137-45.

31. Toutain PL, Bousquet-Melou A. Free drug fraction vs free drug concentration: a matter of frequent confusion. J Vet Pharmacol Ther. 2002;25:460-3.

32. Musteata FM. Calculation of normalized drug concentrations in the presence of altered plasma protein binding. Clin Pharmacokinet. 2012;51:55-68.

33. Charles B, Norris R, Xiao X, Hague W. Population pharmacokinetics of metformin in late pregnancy. Ther Drug Monit. 2006;28:67-72.

34. Model for individual covariates. In: Data, model and mapping. ${ }^{\odot}$ Lixoft. 2018. https://monolix.lixoft.com/data-and-models/covar iate/. Accessed 12 Jul 2020.

35. Rong Y, Mayo P, Ensom MHH, Kiang TKL. Population pharmacokinetics of mycophenolic acid co-administered with tacrolimus in corticosteroid-free adult kidney transplant patients. Clin Pharmacokinet. 2019;58:1483-95.

36. Rong Y, Mayo P, Ensom MHH, Kiang TKL. Population pharmacokinetic analysis of immediate-release oral tacrolimus co-administered with mycophenolate mofetil in corticosteroid-free adult kidney transplant recipients. Eur J Drug Metab Pharmacokinet. 2019;44:409-22.

37. Patsalos PN, Spencer EP, Berry DJ. Therapeutic drug monitoring of antiepileptic drugs in epilepsy: a 2018 update. Ther Drug Monit. 2018;40:526-48.

38. Winter ME. Phenytoin and fosphenytoin. In: Murphy JE, editor. Clinical pharmacokinetics. 6th ed. Bethesda: American Society of Health-System Pharmacists; 2017. p. 333-350.

39. Kiang TKL, Sherwin CMT, Spigarelli MG, Ensom MHH. Fundamentals of population pharmacokinetic modelling: modelling and software. Clin Pharmacokinet. 2012;51:515-25.

40. Sherwin CMT, Kiang TKL, Spigarelli MG, Ensom MHH. Fundamentals of population pharmacokinetic modelling: validation methods. Clin Pharmacokinet. 2012;51:573-90.

41. Appendix B. Common Laboratory Tests. In: Chisholm-Burns MA, Wells BG, Schwinghammer TL, Malone PM, Kolesar JM, Dipiro JT, editors. Pharmacotherapy: principles and practice. 3rd ed. New York: McGraw-Hill Education; 2013. p. 1813-1818. 
42. Howanitz PJ, Darcy TP, Meier FA, Bashleben CP. Assessing clinical laboratory quality: a College of American Pathologists Q-Probes study of prothrombin time INR structures, processes, and outcomes in 98 laboratories. Arch Pathol Lab Med. 2015;139:1108-14.

43. Vossler DG, Weingarten M, Gidal BE, American Epilepsy Society Treatments Committee. Summary of antiepileptic drugs available in the United States of America: working toward a world without epilepsy. Epilepsy Curr. 2018;18:1-26.

44. Aarons L, Ahmed IA, Deleu D. Estimation of population pharmacokinetic parameters of free-phenytoin in adult epileptic patients. Arch Med Res. 2005;36:49-53.

45. Gugler R, Manion CV, Azarnoff DL. Phenytoin: pharmacokinetics and bioavailability. Clin Pharmacol Ther. 1976;19:135-42.

46. Mould DR, Upton RN. Basic concepts in population modeling, simulation, and model-based drug development-part 2: introduction to pharmacokinetic modeling methods. CPT Pharmacometrics Syst Pharmacol. 2013;2:e38.

47. Karlsson MO, Savic RM. Diagnosing model diagnostics. Clin Pharmacol Ther. 2007;82:17-20.

48. Montgomery MC, Chou JW, McPharlin TO, Baird GS, Anderson GD. Predicting unbound phenytoin concentrations: effects of albumin concentration and kidney dysfunction. Pharmacotherapy. 2019;39:756-66.

49. Grasela TH, Sheiner LB, Rambeck B, Boenigk HE, Dunlop A, Mullen PW, Wadsworth J, Richens A, Ishizaki T, Chiba K, Miura H, Minagawa K, Blain PG, Mucklow JC, Bacon CT, Rawlins M. Steady-state pharmacokinetics of phenytoin from routinely collected patient data. Clin Pharmacokinet. 1983;8:355-64.

50. Miller R, Rheeders M, Klein C, Suchet I. Population pharmacokinetics of phenytoin in South African black patients. S Afr Med J. 1987;72:188-90.

51. Ku LC, Wu H, Greenberg RG, Hill KD, Gonzalez D, Hornik CP, Berezny A, Guptill JT, Jiang W, Zheng N, Cohen-Wolkowiez M, Melloni C. Use of therapeutic drug monitoring, electronic health record data, and pharmacokinetic modeling to determine the therapeutic index of phenytoin and lamotrigine. Ther Drug Monit. 2016;38:728-37.

52. Alqahtani S, Alzaidi T, Alotaibi M, Alsultan A. Estimation of phenytoin pharmacokinetic parameters in Saudi epileptic patients. Pharmacology. 2019;104:60-6.

53. Odani A, Hashimoto Y, Takayanagi K, Otsuki Y, Koue T, Takano M, Yasuhara M, Hattori H, Furusho K, Inui K. Population pharmacokinetics of phenytoin in Japanese patients with epilepsy: analysis with a dose-dependent clearance model. Biol Pharm Bull. 1996;19:444-8.

54. Ismail R, Rahman AFA, Chand P. Pharmacokinetics of phenytoin in routine clinic patients in Malaysia. J Clin Pharm Ther. 1994;19:245-8.

55. Abduljabbar M, Al-Khamis K, Ogunniyi A, Daif AK, Al-Yamani M. Phenytoin dosage adjustment in Saudi epileptics: utilization of steady-state pharmacokinetic parameters. Eur J Neurol. 1999;6:331-4.

56. Alimardani S, Sadrai S, Masoumi HT, Salari P, Najafi A, Eftekhar B, Mojtahedzadeh M. Pharmacokinetic behavior of phenytoin in head trauma and cerebrovascular accident patients in an Iranian population. J Res Pharm Pract. 2017;6:217-22.

57. Chavda HV, Patel CN, Anand IS. Biopharmaceutics classification system. Sys Rev Pharm. 2010;1:62-9.

58. Ebadi M, Mazurak VC. Evidence and mechanisms of fat depletion in cancer. Nutrients. 2014;6:5280-97.

59. Weber DR, Leonard MB, Zemel BS. Body composition analysis in the pediatric population. Pediatr Endocrinol Rev. 2012;10:130-9.
60. Deitchman AN, Singh RSP, Derendorf H. Nonlinear protein binding: not what you think. J Pharm Sci. 2018;107:1754-60.

61. Sellers EM, Koch-Weser J. Clinical implications of drug-albumin interaction. In: Rosenoer VM, Oratz M, Rothschild MA, editors. Albumin: structure, function and uses. 1st ed. Oxford: Pergamon Press; 1977. p. 159-182.

62. Verbeeck RK. Pharmacokinetics and dosage adjustment in patients with hepatic dysfunction. Eur J Clin Pharmacol. 2008;64:1147-61.

63. Mabuchi $\mathrm{H}, \mathrm{Nakahashi} \mathrm{H}$. A major inhibitor of phenytoin binding to serum protein in uremia. Nephron. 1988;48:310-4.

64. Dasgupta A, Malik S. Fast atom bombardment mass spectrometric determination of the molecular weight range of uremic compounds that displace phenytoin from protein binding: absence of midmolecular uremic toxins. Am J Nephrol. 1994;14:162-8.

65. Barnes KJ, Rowland A, Polasek TM, Miners JO. Inhibition of human drug-metabolising cytochrome $\mathrm{P} 450$ and UDP-glucuronosyltransferase enzyme activities in vitro by uremic toxins. Eur J Clin Pharmacol. 2014;70:1097-106.

66. Leonard RF, Knott PJ, Rankin GO, Robinson DS, Melnick DE. Phenytoin-salicylate interaction. Clin Pharmacol Ther. 1981;29:56-60.

67. Zaccara G, Perucca E. Interactions between antiepileptic drugs, and between antiepileptic drugs and other drugs. Epileptic Disord. 2014;16:409-31.

68. Nation RL, Evans AM, Milne RW. Pharmacokinetic drug interactions with phenytoin (Part I). Clin Pharmacokinet. 1990;18:37-60.

69. Lecomte M, Zini R, d'Athis P, Tillement JP. Phenytoin binding to human albumin. Eur J Drug Metab Pharmacokinet. 1979;4:23-8.

70. Céspedes-Garro C, Fricke-Galindo I, Naranjo MEG, RodriguesSoares F, Fariñas H, de Andrés F, López-López M, Peñas-Lledó EM, LLerena A. Worldwide interethnic variability and geographical distribution of CYP2C9 genotypes and phenotypes. Expert Opin Drug Metab Toxicol. 2015;11:1893-905.

71. Rettie AE, Haining RL, Bajpai M, Levy RH. A common genetic basis for idiosyncratic toxicity of warfarin and phenytoin. Epilepsy Res. 1999;35:253-5.

72. Chen LG, Wang Z, Zhu Y, Xiong JH, Sun LR, Dai DP, Cai JP, Hu GX. In vitro metabolism of phenytoin in 36 CYP2C9 variants found in the Chinese population. Chem Biol Interact. 2016;253:93-9.

73. Caudle KE, Rettie AE, Whirl-Carrillo M, Smith LH, Mintzer S, Lee MTM, Klein TE, Callaghan JT, Clinical Pharmacogenetics Implementation Consortium. Clinical Pharmacogenetics Implementation Consortium guidelines for CYP2C9 and HLA-B genotypes and phenytoin dosing. Clin Pharmacol Ther. 2014;96:542-8.

74. Kesavan R, Narayan SK, Adithan C. Influence of CYP2C9 and CYP2C19 genetic polymorphisms on phenytoin-induced neurological toxicity in Indian epileptic patients. Eur J Clin Pharmacol. 2010;66:689-96.

75. Depondt C, Godard P, Espel RS, Da Cruz AL, Lienard P, Pandolfo M. A candidate gene study of antiepileptic drug tolerability and efficacy identifies an association of CYP2C9 variants with phenytoin toxicity. Eur J Neurol. 2011;18:1159-64.

76. Hennessy S, Leonard CE, Freeman CP, Metlay JP, Chu X, Strom BL, Bilker WB. CYP2C9, CYP2C19, and ABCB1 genotype and hospitalization for phenytoin toxicity. J Clin Pharmacol. 2009;49:1483-7.

77. Kragh-Hansen U, Minchiotti L, Galliano M, Peters T Jr. Human serum albumin isoforms: genetic and molecular aspects and functional consequences. Biochim Biophys Acta. 2013;1830:5405-17. 